\title{
Plasma riboflavin concentration as novel indicator for vitamin-B2 status assessment: suggested cutoffs and its association with vitamin-B6 status in women
}

\section{Abstract}

Riboflavin (vitamin B2), as the coenzymes flavin mononucleotide (FMN) and flavin dinucleotide (FAD), is essential for oxidationreduction reactions and energy metabolism. Riboflavin also interacts with vitamin B12, B6 and folate in one-carbon metabolism, and is required for the conversion of dietary vitamin B6 forms to the coenzyme pyridoxal 5'-phosphate (PLP). Biochemical riboflavin status is rarely measured given the lack of convenient and accessible biomarkers. The current gold-standard marker is erythrocyte glutathione reductase activation coefficient (EGRac) that involves laborious sample processing. High prevalence of riboflavin deficiency (EGRac $\geq 1.4$ ) and suboptimal status (EGRac of 1.3-1.39) have been reported in the UK and Ireland; yet the functional significance is unclear. Plasma riboflavin concentration may serve as an alternative indicator; its association with related metabolites has not yet been investigated. Secondary analysis was conducted to determine the change-point of plasma riboflavin with EGRac, to derive a reference interval for plasma riboflavin, and to determine the association of riboflavin status with plasma PLP, using data of 223 older adult women from a cross-sectional study. Fasting blood samples and sociodemographic, anthropometric and dietary data were available for a convenience sample of 223 older adult women. Plasma PLP and related metabolites were quantified using isotopedilution liquid chromatography-tandem mass spectrometry. The change-point $(95 \% \mathrm{CI})$ between EGRac and plasma riboflavin occurred at plasma riboflavin concentration of $26.5(20.5 ; 32.5) \mathrm{nmol} / \mathrm{L}$ (with EGRac of 1.25$)$. The median (IQR) plasma riboflavin concentration was $15.7(11.2,23.8)$; and the upper and lower limits $(90 \% \mathrm{CI})$ of the central $95 \%$ reference interval were $6.70(6.33,7.79)$ and $64.2(55.0,74.6) \mathrm{nmol} / \mathrm{L}$, respectively. Plasma PLP (geometric mean $(95 \% \mathrm{CI})$ ) was significantly lower in women with riboflavin deficiency, $54.0(46.8,62.2) \mathrm{nmol} / \mathrm{L}(n=64)$, and suboptimal riboflavin status, $56.1(48.9,64.3) \mathrm{nmol} / \mathrm{L}(n=48)$, compared to those with riboflavin adequacy, $135(112,161) \mathrm{nmol} / \mathrm{L}(n=110)$. Plasma PLP was positively associated with plasma riboflavin concentration after adjustment for total B6 intake, age, ethnicity, BMI, education, household income and C-reactive protein concentration $[\beta(95 \%$ $\mathrm{CI})=1.92(.670,3.17) \mathrm{nmol} / \mathrm{L} ; \mathrm{p}=0.003]$; a significant interaction between plasma riboflavin and total dietary B6 intake was observed $(\mathrm{p}=0.024)$. In conclusion, we are presenting for the first time a reference range for plasma riboflavin concentration and its changepoint with EGRac in healthy women. Vitamin B6 status is strongly associated with riboflavin status; more research is needed to elucidate this relationship in a larger sample and ideally intervention study.

\section{Conflict of Interest}

There is no conflict of interest 